\title{
What Does the Boxed Warning Tell Us? Safe Practice of Using Ferumoxytol as an MRI Contrast Agent
}

\author{
(D) C.G. Varallyay, (D) G.B. Toth, (D) R. Fu, (D).P. Netto, (D). Firkins, (D) P. Ambady, and (DE.A. Neuwelt
}

\begin{abstract}
BACKGROUND AND PURPOSE: Despite the label change and the FDA's boxed warning added to the Feraheme (ferumoxytol) label in March 2015, radiologists have shown increasing interest in using ferumoxytol as an MR imaging contrast agent as a supplement or alternative to gadolinium. The goals of this study were to provide information regarding ferumoxytol safety as an imaging agent in a single center and to assess how the Feraheme label change may affect this potential, currently off-label indication.
\end{abstract}

MATERIALS AND METHODS: This retrospective study evaluated the overall frequency of ferumoxytol-related adverse events when used for CNS MR imaging. Patients with various CNS pathologies were enrolled in institutional review board-approved imaging studies. Ferumoxytol was administered as multiple rapid bolus injections. The risk of adverse events was correlated with demographic data/ medical history.

RESULTS: The safety of 671 ferumoxytol-enhanced MR studies in 331 patients was analyzed. No anaphylactic, life-threatening, or fatal (grade 4 or 5) adverse events were recorded. The overall proportion of ferumoxytol-related grade 1-3 adverse events was $10.6 \%$ (8.6\% occurring within 48 hours), including hypertension (2.38\%), nausea (1.64\%), diarrhea (1.04\%), and headache (1.04\%). History of 1 or 2 allergies was associated with an increased risk of adverse events (14.61\% versus $7.51 \%$ [no history]; $P=.007$ ).

CONCLUSIONS: The frequency of mild ferumoxytol-related adverse events was comparable with literature results, and no serious adverse event was recorded. Although the recommendations in the boxed warning should be followed, serious adverse events appear to be rare, and with proper precautions, ferumoxytol may be a valuable MR imaging agent.

ABBREVIATIONS: $\mathrm{AE}=$ adverse event; $\mathrm{CTCAE}=$ Common Terminology Criteria for Adverse Events; HSR $=$ hypersensitivity reaction

$\mathbf{F}$ erumoxytol, marketed as Feraheme (AMAG Pharmaceuticals, Waltham, Massachusetts), is an ultra-small iron oxide nanoparticle approved to treat iron deficiency anemia in adults with chronic kidney disease. ${ }^{1}$ Because of its superparamagnetic prop-

Received December 22, 2016; accepted after revision February 17, 2017.

From the Departments of Radiology (C.G.V., J.P.N.), Neurology (C.G.V., G.B.T., J.P.N., J.F., P.A., E.A.N.), Medical Informatics and Clinical Epidemiology (R.F.), and Neurosurgery (E.A.N.) and School of Public Health (R.F.), Oregon Health \& Science University, Portland, Oregon; and Portland Veterans Affairs Medical Center (E.A.N.), Portland, Oregon.

This work was supported by National Institutes of Health grants NS053468, CA199111, and CA137488-15S1, in part with Federal funds from the National Cancer Institute, National Institutes of Health, under Contract No. HHSN261200800001E, and by the Walter S. and Lucienne Driskill Foundation (all to E.A.N).

Paper previously presented at: Annual Meeting of the Radiological Society of North America, November 29-December 4, 2015; Chicago, Illinois.

Please address correspondence to Edward A. Neuwelt, MD, Oregon Health \& Science University, 3181 SW Sam Jackson Park Rd, L603, Portland, OR 97239; e-mail: neuwelte@ohsu.edu

- Indicates open access to non-subscribers at www.ajnr.org

三 Indicates article with supplemental on-line tables.

http://dx.doi.org/10.3174/ajnr.A5188 erties, ferumoxytol can be used as an MR imaging contrast agent. ${ }^{2}$ Despite the label change and the FDA's boxed warning about possible serious hypersensitivity reactions (HSR) added to the Feraheme label in March 2015, radiologists have shown increasing interest in using ferumoxytol as an MR imaging contrast agent because the long plasma half-life and the lack of early leakage allow imaging of the intravascular space early after injection. ${ }^{3-7}$ Delayed MR imaging (24 hours after ferumoxytol administration) shows blood-brain barrier defects similar to gadolinium agents, which makes it a potential alternative if gadolinium-based contrast agents are contraindicated. ${ }^{8,9}$ Delayed ferumoxytol imaging can also take advantage of intracellular uptake of the nanoparticles to image inflammation ${ }^{10}$ or assess the lymph nodes for tumor staging. ${ }^{11-14}$

There are limited safety data of ferumoxytol as an MR imaging contrast agent in the literature. A recent study analyzing 65 cases of children and young adults from institutional review boardapproved imaging studies concluded that ferumoxytol was well tolerated as an MR imaging agent. ${ }^{15}$ Another publication re- 
ported a single anaphylactoid reaction in 2000 off-label uses of ferumoxytol for MR imaging, ${ }^{16}$ whereas a recently published single-center investigation with 217 patients showed no serious adverse events (AEs) with the diagnostic use of ferumoxytol. ${ }^{17}$ Our institution has more than 10 years of experience using ferumoxytol as an MR imaging contrast agent in the CNS in patients with or without compromised renal function and, as of December 31, 2015, had completed $671 \mathrm{MR}$ imaging studies with ferumoxytol in 8 institutional review board-approved imaging protocols in which AEs were closely monitored. These are the largest singleinstitution safety data of ferumoxytol used in imaging research protocols. Detailed demographic information was collected, and patients were followed-up for 6 weeks after ferumoxytol administration. The goals of this study were to provide information regarding the safety of ferumoxytol as an MR imaging contrast agent and to assess how the ferumoxytol label change may affect this potential, currently off-label indication.

\section{MATERIALS AND METHODS}

\section{Ferumoxytol Administration}

This retrospective, single-center study analyzed the safety data of 671 ferumoxytol injections in 331 patients between June 2004 and December 2015. The average age of the patients was 51.08 years (SD, \pm 16.82 years), and the female-male ratio was 1:1.33. All patients signed informed consent and were enrolled in 1 of the 8 institutional review board-approved ferumoxytol imaging protocols (On-line Table 1).

In all cases, ferumoxytol was given during MR imaging by using 1 or multiple IV bolus injections (1:1 or 1:2 diluted ferumoxytol, $3 \mathrm{~mL} / \mathrm{s}$ flow rate, with $20-\mathrm{mL}$ saline flush at the same flow rate). In most studies, the first $1 \mathrm{mg} / \mathrm{kg}$ (or $75 \mathrm{mg}$ ) was used for dynamic perfusion imaging, with the remaining dose administered in 1 or 2 subsequent bolus injections. The full $4-7 \mathrm{mg} / \mathrm{kg}$ or $510 \mathrm{mg}$ was never given as a single injection. Subsequent to the label changes and boxed warning, infusion parameters were modified in all protocols, as Fig 1 indicates. Patients were evaluated for AEs after each ferumoxytol injection. Blood pressure, pulse, and oxygen saturation were recorded before and after each injection. Patients were observed for at least 30 minutes after the completion of ferumoxytol administration. A research nurse or physician was always present during ferumoxytol administration, the postcontrast MR imaging acquisition, and the following observation period.

\section{Recording Adverse Events}

Data on AEs were recorded according to Common Terminology Criteria for Adverse Events v3.0 or v4.0 (CTCAE), ${ }^{18,19}$ including the description of the toxicity event, toxicity category, toxicity grade, time of occurrence after ferumoxytol injection, and toxicity attribute. Attribute describes the likelihood that the AE was caused by ferumoxytol based on clinical judgment and has 5 categories: 1 , unrelated; 2 , unlikely; 3 , possible; 4 , probably; and 5 , definite. We only included AEs that occurred within 6 weeks (42 days) of each ferumoxytol injection. Patients were contacted by phone by a research nurse or completed a clinic visit 6 weeks after administration of ferumoxytol to assess for any AEs. Patient characteristics such as age, race, sex, existence of allergies, steroid use, pathology, and administered ferumoxytol dose were also re-
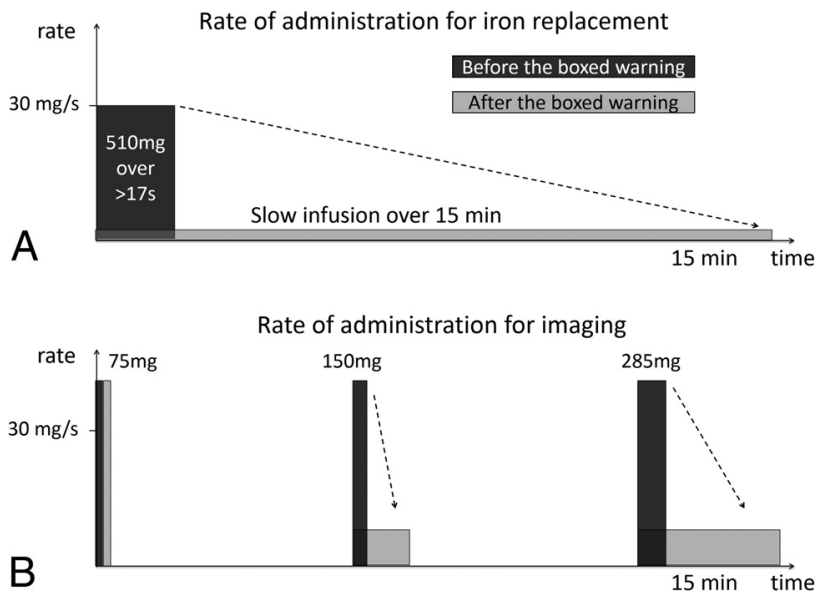

FIG 1. Rate of ferumoxytol administration; for iron replacement $(A)$, the prior label allowed bolus injection of $510 \mathrm{mg}$ of ferumoxytol not faster than 17 seconds (equivalent to $30 \mathrm{mg} / \mathrm{s} \mathrm{Fe}$ ). The current label recommends slow infusion of diluted ferumoxytol over 15 minutes. For imaging, which is still an off-label indication, we used to administer ferumoxytol in 2 or 3 rapid bolus injections. Panel B shows ferumoxytol administration of protocol \#1562, in which a full vial of $510 \mathrm{mg}$ was given. As a response to the boxed warning, only the initial $75 \mathrm{mg}$ is injected as before $(3 \mathrm{~mL} / \mathrm{s}$ of 1:1 diluted ferumoxytol, equivalent to $45 \mathrm{mg} / \mathrm{s} \mathrm{Fe}$ ), and dynamic perfusion data are acquired. The other ongoing protocols have been adjusted accordingly; only the first $1 \mathrm{mg} / \mathrm{kg}$ being injected as a bolus.

corded. On-line Table 2 shows the potential AEs with ferumoxytol classified to CTCAE and FDA categories. Note that CTCAE grade 3 (severe) AEs may or may not be serious based on FDA classification. ${ }^{18-20}$ Serious AEs are associated with specific outcomes (eg, life-threatening or hospitalization). In contrast, a "severe nosebleed" may not qualify as being categorized as serious.

\section{Statistical Methods}

Descriptive statistics were used to summarize patient demographics and clinical characteristics. AEs with an attribute of 3 , 4, or 5 were characterized, including at least $1 \mathrm{AE}$ in an infusion, early $\mathrm{AE}$ (occurring within 48 hours of ferumoxytol administration), and $\mathrm{AE}$ by event type by using proportions. Association between at least $1 \mathrm{AE}$ in an infusion and patient characteristics was assessed by using a logistic generalized estimating equation model while taking into account the correlation of multiple infusions within a patient. The statistical package SAS 9.4 (SAS Institute, Cary, North Carolina) was used.

\section{RESULTS}

Among the 671 ferumoxytol infusions, grade 1, 2, or 3 AEs occurred in 71 infusions (10.6\%) recorded within 6 weeks. Most AEs occurred within 48 hours after ferumoxytol infusion (in 58 cases [ $8.6 \%$ of the infusions]). There were no life-threatening or fatal (grade 4 or 5) AEs. The most frequent mild and moderate AEs were hypertension $(2.38 \%)$, nausea $(1.64 \%)$, diarrhea $(1.04 \%)$, and headache (1.04\%) (Fig 2). Only 2 grade 3 AEs were recorded $(0.30 \%)$. One patient had a rapid rash on his trunk, both upper extremities, and thighs after the imaging. He received IV dexamethasone, and after several hours of observation, all symptoms disappeared with no further treatment needed. Another patient, who developed red sclera with burning/tingling sensation after an otherwise uneventful ferumoxytol MR imaging, returned for a 
second study visit 6 months later. Immediately after the initial 1 $\mathrm{mg} / \mathrm{kg}$ ferumoxytol administration, he reported severe nausea and moderate degree of shortness of breath along with lower back pain. The patient was removed from the scanner, and no further ferumoxytol was given. He was treated with albuterol and diphenhydramine, and the symptoms completely subsided after 2 hours.

In the logistic generalized estimating equation model, patients with 1 or 2 pre-existing allergies were more likely to have at least 1 AE after ferumoxytol infusion compared with patients without any pre-existing allergy ( $14.6 \%$ versus $7.5 \% ; P=.007)$. No other patient characteristics showed significant association with the occurrence of AE (Table 1).

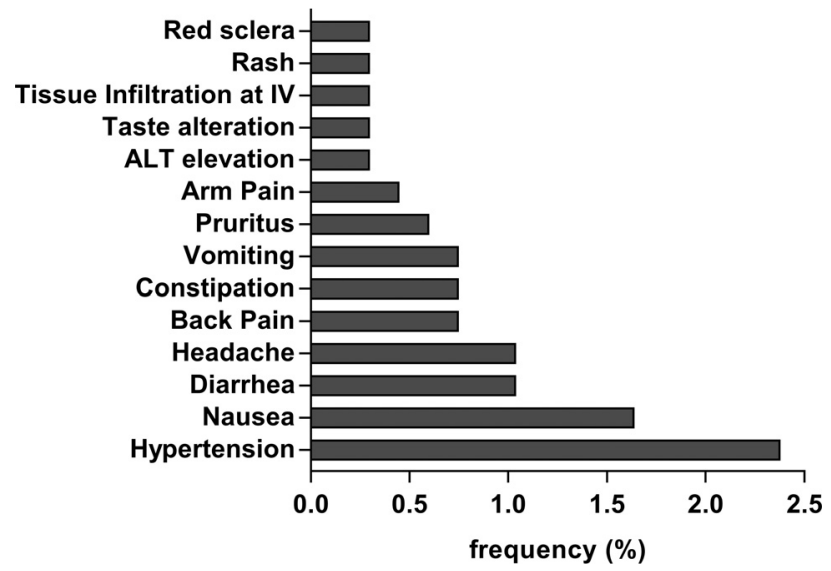

FIG 2. Frequency of AEs potentially related to ferumoxytol. Events that occurred in at least 2 cases are displayed. Note that multiple AEs (symptoms, abnormal lab values) may be associated with a single injection according to the CTCAE recording guidelines.

\section{DISCUSSION}

Contrast materials are frequently used in imaging and provide valuable information, often changing the course of treatment. Contrast agents are known to be generally safe, with minimal risk of HSR. ${ }^{21}$ Our results showed that overall ferumoxytol-related AE occurred in $10.6 \%$ of infusions, most of them occurring within 48 hours $(8.6 \%)$, in concordance with $10 \%-14.6 \%$ of AE published in the literature based on 3 randomized trials for iron replacement. ${ }^{22-24}$ Based on our data, the frequency of AE with Feraheme is equivalent to ionic iodinated contrast media, approximately 15 times higher than gadolinium MR contrast agents, and 4 times higher than nonionic iodinated contrast agents, ${ }^{25,26}$ which is summarized in Table 2. Severe reactions, based on literature data, occur 6-7 times more often with ferumoxytol compared with gadolinium or currently used nonionic iodinated agents.

At our institution, we have not recorded any serious AEs with ferumoxytol. However, we acknowledge that our sample size may not be adequate to record this rare event. It is worth mentioning that our patient population may differ from populations reported in prior studies because most of our patients had brain tumors; it has been shown that patients with tumor can be anergic ${ }^{27-29}$ and are often on corticosteroids, which may cause immunosuppression and, in theory, help prevent HSR. ${ }^{30}$ Our results, however, did

Table 2: Frequency of adverse events using various contrast media from the literature and our data

\begin{tabular}{lcc}
\hline \multicolumn{1}{c}{ Contrast Media } & $\begin{array}{c}\text { Adverse } \\
\text { Events }\end{array}$ & $\begin{array}{c}\text { Severe } \\
\text { Adverse Events }\end{array}$ \\
\hline Gadolinium $^{25}$ & $0.8 \%$ & $0.03 \%$ \\
lodinated (ionic) $^{26}$ & $12.66 \%$ & $0.22 \%$ \\
lodinated (nonionic) $^{26}$ & $3.13 \%$ & $0.04 \%$ \\
Ferumoxytol (Feraheme label) $_{\text {Ferumoxytol (our data) }}^{3.7 \%}$ & $0.2 \%$ \\
\hline
\end{tabular}

Table 1: Patient characteristics

\begin{tabular}{|c|c|c|c|c|c|}
\hline Characteristics & Infusions, No. & $\begin{array}{l}\text { Infusions With At } \\
\text { Least } 1 \text { Event }\end{array}$ & $\begin{array}{c}\% \text { of Infusions With } \\
\text { At Least } 1 \text { Event }\end{array}$ & Odds Ratio & $P$ Value $^{\mathrm{a}}$ \\
\hline \multicolumn{6}{|l|}{ Age } \\
\hline$<70$ yrs & 634 & 67 & 10.6 & Reference & .91 \\
\hline$>70 \mathrm{yrs}$ & 37 & 4 & 10.8 & $1.06(0.37,3.02)$ & \\
\hline \multicolumn{6}{|l|}{ Race } \\
\hline White & 645 & 68 & 10.5 & Reference & .87 \\
\hline Non-white & 26 & 3 & 11.5 & $1.10(0.35,3.50)$ & \\
\hline \multicolumn{6}{|l|}{ Gender } \\
\hline Female & 272 & 33 & 12.1 & Reference & .38 \\
\hline Male & 399 & 38 & 9.5 & $0.79(0.47,1.33)$ & \\
\hline Number of existing allergies & & & & & $.026^{\mathrm{b}}$ \\
\hline 0 & 333 & 25 & 7.5 & Reference & \\
\hline 1 or 2 & 268 & 39 & 14.6 & $2.13(1.23,3.70)$ & $.007^{c}$ \\
\hline$>2$ allergies & 70 & 7 & 10 & $1.35(0.58,3.17)$ & .49 \\
\hline Ferumoxytol dose & & & & & $.40^{\mathrm{b}}$ \\
\hline$\leq 2 \mathrm{mg} / \mathrm{kg}$ & 121 & 8 & 6.6 & Reference & \\
\hline $2-4 \mathrm{mg} / \mathrm{kg}$ & 303 & 34 & 11.2 & $1.77(0.69,4.54)$ & .23 \\
\hline$>4 \mathrm{mg} / \mathrm{kg}$ & 247 & 29 & 11.7 & $1.86(0.75,4.58)$ & .18 \\
\hline \multicolumn{6}{|l|}{ Steroid use } \\
\hline None & 461 & 44 & 9.5 & Reference & .13 \\
\hline On decadron & 183 & 25 & 13.7 & $1.56(0.92,2.67)$ & \\
\hline \multicolumn{6}{|l|}{ Pathology } \\
\hline Non-tumor & 54 & 5 & 9.3 & Reference & .71 \\
\hline Tumor & 617 & 66 & 10.7 & $1.20(0.47,3.04)$ & \\
\hline
\end{tabular}

a $P$ values are obtained from the logistic generalized estimating equation model.

${ }^{b}$ Overall $P$ value for the number of existing allergies or ferumoxytol dose.

c Statistically significant. 
not show any risk reduction in patients with long-term corticosteroid use, nor in those with tumor pathology. The benefit of premedication before IV iron products remains controversial in the literature and is generally not advised. ${ }^{31}$

Although the 2 grade 3 reactions were possibly HSR-related, most of the AEs recorded in this study are likely unrelated to HSR. Hypertension, recorded most frequently after ferumoxytol injection, may be anxiety-related, which normalized without intervention by the time the patient left the MR imaging suite. No ferumoxytol-related blood pressure drop has been detected. Our study found a significant association between 1 or 2 existing allergies and the frequency of mild AEs. The exact mechanism of iron HSR is still unclear. Bioactive, labile iron, which is present in all IV iron products, may be an important causative factor. Complement activation-related pseudoallergy, triggered by iron nanoparticles, is probably a more frequent mechanism in acute reactions to current IV formulations than is an immunologic IgEmediated response. $^{32}$

The boxed warning of Feraheme is intended to mitigate the risk and potential morbidity of HSR, thus enhancing patient safety. Recommendations are to observe patients up to $30 \mathrm{~min}$ utes after injection and monitor heart rate and blood pressure at baseline and after (each) ferumoxytol administration, which was re-emphasized in this warning and which we strictly adhere to in our imaging protocols. Rapid bolus injection (previously up to 30 $\mathrm{mg} / \mathrm{s}$ ) was eliminated from the package insert, and infusion of the diluted ferumoxytol over 15 minutes became the recommendation. Although there are currently no data using ferumoxytol to support that slow infusion is indeed safer than bolus injection, slow infusion is recommended with other iron products ${ }^{32}$ and it also allows observation of the patient during ferumoxytol administration and termination of the infusion if HSR occurs.

For MR imaging, to best comply with FDA recommendations, rapid bolus should be avoided. Our imaging protocols have eliminated rapid injection, and only the first $1 \mathrm{mg} / \mathrm{kg}$ is given as a bolus to gain clinically valuable dynamic imaging data. The lack of contrast agent leakage has been demonstrated as a benefit compared with low molecular weight agents, though the latter ones may be corrected with mathematical algorithms. ${ }^{33}$ For most imaging applications, such as high-resolution steady-state blood volume mapping, steady-state angiography, and visualization of delayed ferumoxytol enhancement/inflammation, no bolus injection is necessary; therefore, high flow rate injection may be completely avoided.

The new prescribing information as of March 2015 provides additional information regarding the potential for more severe HSR in elderly patients with multiple or serious comorbidities and increased risk of HSR to Feraheme in patients with a history of multiple drug allergies. This information may be useful when considering risk and benefit.

A detailed analysis and guideline have been published by an international group to minimize the risk and severity of IV iron supplement-related AEs. There is emphasis on observation, prompt recognition of symptoms, and severity-related interventions by well-trained medical and nursing staff. ${ }^{32}$ On-line Table 3 summarizes our recommendations in managing hypersensitivity related to IV iron, when used as an MR contrast agent.
Contrast agent safety is a relevant clinical issue. HSR is just one of the contrast agent-related AEs; in gadolinium-based agents, the incidence of nephrogenic systemic fibrosis has been minimized since the guidelines and boxed warning. Given the emerging safety record of macrocyclic contrast agents in patients with renal failure, remaining contraindications are rare and limited essentially to a history of rare severe allergic reaction to gadolinium-based agents. Gadolinium deposition in the nervous system is a recent finding, which occurs even in patients with normal renal function, and its clinical impact is still unknown. ${ }^{34}$ Although no serious AE with ferumoxytol was observed in 671 administrations at our institution, it is important to understand the potential risks and be prepared in case a severe reaction occurs. Having trained staff and appropriate medications available would be considered good medical practice in any facility using any imaging contrast agent.

The limitations of ferumoxytol imaging include potential iron overload in patients with iron metabolism disorders. The maximum administered dose $(510 \mathrm{mg})$ is equivalent with 2 units of blood, which is unlikely to cause acute or chronic toxicity in patients with normal iron metabolism. ${ }^{15}$ Ferumoxytol is taken up by the liver, spleen, and bone marrow, which may cause signal change on the MR imaging for months. In the CNS, contrast enhancement may be detectable a few days after administration. Adding another contrast agent (ie, if used in addition to gadolinium-based contrast agents) may increase the costs, in addition to MR imaging time, if additional imaging is used. Our research protocols included up to 3 consecutive days of scanning, and MR imaging times were long: between 60-90 minutes on days when contrast agent was given and 30-45 minutes to image late ferumoxytol enhancement. In clinical practice, however, more focused imaging is applied to answer the clinical question. Highresolution blood volume maps may be obtained with only an additional 5 minute scan time. ${ }^{5}$ Steady-state angiography requires only a few minutes of scan time, whereas late enhancement/imaging inflammation/lymph node imaging requires a separate MR imaging scanning session, which is likely the length of a noncontrast MR imaging study. Multiphase contrast administration was used to test the optimal doses for various applications, but in clinical use, a single infusion of the most appropriate dose is sufficient. Applications, such as visualizing the micro- and macrovasculature and visualizing inflammation, hold promise, but future trials have to prove their impact on improving clinical diagnosis and clinical management.

Limitations of this study include the variable patient characteristics and ferumoxytol doses. Although our sample size of 671 was the highest reported in a single center, this number is still too low to evaluate the frequency of rare, but serious HSR.

\section{CONCLUSIONS}

The safety of 671 well-documented cases of using ferumoxytol as an MR imaging agent was reported in this study. The overall occurrence of AEs is in agreement with prior ferumoxytol safety studies, and no serious AE was observed. Although the AE is more frequent compared with gadolinium, and there may be increased costs, emerging new MR imaging applications may justify the use of ferumoxytol as an MR imaging contrast agent. The recommen- 
dations in the boxed warning should be followed to further improve the safety of imaging with ferumoxytol.

Disclosures: Rongwei Fu_UNRELATED: Grants/Grants Pending: Oregon Health \& Science University*. Jenny Firkins—RELATED: Grants/Grants Pending: Driskill Foundation grant and R01*; UNRELATED: Employment: Driskill Foundation grant and R01. Edward Neuwelt-RELATED: Grants/Grants Pending: National Institutes of Health, Driskill Foundation, Comments: This work was supported in part by National Institutes of Health grants NS053468, CA199111, and CA137488-15S1, in part with Federal funds from the National Cancer Institute, National Institutes of Health, under Contract No. HHSN261200800001E, and by the Walter S. and Lucienne Driskill Foundation, all to E.A.N.; UNRELATED: Grants/Grants Pending: AMAG Pharmaceuticals, Comments: Dr. Neuwelt's studies involving ferumoxytol were entirely funded by National Institutes of Health research grants and the Driskill Foundation, with the ferumoxytol ultra-small superparamagnetic iron oxide nanoparticles donated by AMAG Pharmaceuticals. Oregon Health \& Science University has received a small sponsored research agreement from AMAG Pharmaceuticals to partially fund clinical trials of MRI with ferumoxytol. None of the authors has financial interest in this agent or in its developer AMAG Pharmaceuticals. ${ }^{*}$ Money paid to the institution.

\section{REFERENCES}

1. Lu M, Cohen MH, Rieves D, et al. FDA report: ferumoxytol for intravenous iron therapy in adult patients with chronic kidney disease. Am J Hematol 2010;85:315-19 CrossRef Medline

2. Bashir MR, Bhatti L, Marin D, et al. Emerging applications for ferumoxytol as a contrast agent in MRI. J Magn Reson Imaging 2015;41: 884-98 CrossRef Medline

3. Hope MD, Hope TA, Zhu C, et al. Vascular imaging with ferumoxytol as a contrast agent. AJR Am J Roentgenol 2015;205:W366-73 CrossRef Medline

4. Nayak AB, Luhar A, Hanudel M, et al. High-resolution, whole-body vascular imaging with ferumoxytol as an alternative to gadolinium agents in a pediatric chronic kidney disease cohort. Pediatr Nephrol 2015;30:515-21 CrossRef Medline

5. Varallyay CG, Nesbit E, Fu R, et al. High-resolution steady-state cerebral blood volume maps in patients with central nervous system neoplasms using ferumoxytol, a superparamagnetic iron oxide nanoparticle. J Cereb Blood Flow Metab 2013;33:780-86 CrossRef Medline

6. Christen T, Ni W, Qiu D, et al. High-resolution cerebral blood volume imaging in humans using the blood pool contrast agent ferumoxytol. Magn Reson Med 2013;70:705-10 CrossRef Medline

7. Finn JP, Nguyen KL, Han F, et al. Cardiovascular MRI with ferumoxytol. Clin Radiol 2016;71:796-806 CrossRef Medline

8. Neuwelt EA, Hamilton BE, Varallyay CG, et al. Ultrasmall superparamagnetic iron oxides (USPIOs): a future alternative magnetic resonance (MR) contrast agent for patients at risk for nephrogenic systemic fibrosis (NSF)? Kidney Int 2009;75:465-74 CrossRef Medline

9. Neuwelt EA, Várallyay CG, Manninger S, et al. The potential of ferumoxytol nanoparticle magnetic resonance imaging, perfusion, and angiography in central nervous system malignancy: a pilot study. Neurosurgery 2007;60:601-11; discussion 611-12 CrossRef Medline

10. Storey P, Arbini AA. Bone marrow uptake of ferumoxytol: a preliminary study in healthy human subjects. J Magn Reson Imaging 2014; 39:1401-10 CrossRef Medline

11. Guthrie PJ, Thomas JV, Peker D, et al. Perivesical unicentric Castleman disease initially suspected to be metastatic prostate cancer. Urol Ann 2016;8:245-48 CrossRef Medline

12. Liu L, Tseng L, Ye Q, et al. A new method for preparing mesenchymal stem cells and labeling with ferumoxytol for cell tracking by MRI. Sci Rep 2016;6:26271 CrossRef Medline

13. Pouw JJ, Grootendorst MR, Bezooijen R, et al. Pre-operative sentinel lymph node localization in breast cancer with superparamagnetic iron oxide MRI: the SentiMAG Multicentre Trial imaging subprotocol. Br J Radiol 2015;88:20150634 CrossRef Medline

14. Wang YX. Current status of superparamagnetic iron oxide contrast agents for liver magnetic resonance imaging. World J Gastroenterol 2015;21:13400-02 CrossRef Medline

15. Muehe AM, Feng D, von Eyben R, et al. Safety report of ferumoxytol for magnetic resonance imaging in children and young adults. Invest Radiol 2016;51:221-27 CrossRef Medline

16. Vasanawala SS, Nguyen KL, Hope MD, et al. Safety and technique of ferumoxytol administration for MRI. Magn Reson Med 2016;75: 2107-11 CrossRef Medline

17. Nguyen KL, Yoshida T, Han F, et al. MRI with ferumoxytol: a single center experience of safety across the age spectrum. J Magn Res Imaging 2017;45:804-12 CrossRef Medline

18. Common Terminology Criteria for Adverse Events v3.0 (CTCAE). Published August 9, 2006. https://ctep.cancer.gov/protocolDevelopment/ electronic_applications/docs/ctcaev3.pdf. Accessed April 3, 2017

19. Common Terminology Criteria for Adverse Events (CTCAE) Version 4.0. Published 2010. https://ctep.cancer.gov/protocolDevelopment/ electronic_applications/ctc.htm. Accessed April 3, 2017

20. What is a serious adverse event? U.S. Food and Drug Administration. https://www.fda.gov/safety/medwatch/howtoreport/ucm053087. htm. Accessed May 4, 2017

21. Brockow K, Sánchez-Borges M. Hypersensitivity to contrast media and dyes. Immunol Allergy Clin North Am 2014;34:547-64, viii CrossRef Medline

22. Vadhan-Raj S, Strauss W, Ford D, et al. Efficacy and safety of IV ferumoxytol for adults with iron deficiency anemia previously unresponsive to or unable to tolerate oral iron. Am J Hematol 2014;89: 7-12 CrossRef Medline

23. Macdougall IC, Strauss WE, McLaughlin J, et al. A randomized comparison of ferumoxytol and iron sucrose for treating iron deficiency anemia in patients with CKD. Clin J Am Soc Nephrol 2014;9: 705-12 CrossRef Medline

24. Hetzel D, Strauss W, Bernard K, et al. A phase III, randomized, openlabel trial of ferumoxytol compared with iron sucrose for the treatment of iron deficiency anemia in patients with a history of unsatisfactory oral iron therapy. Am J Hematol 2014;89:646-50 CrossRef Medline

25. Bleicher AG, Kanal E. Assessment of adverse reaction rates to a newly approved MRI contrast agent: review of 23,553 administrations of gadobenate dimeglumine. AJR Am J Roentgenol 2008;191: W307-11 CrossRef Medline

26. Katayama H, Yamaguchi K, Kozuka T, et al. Adverse reactions to ionic and nonionic contrast media. A report from the Japanese Committee on the Safety of Contrast Media. Radiology 1990;175: 621-28 CrossRef Medline

27. Evans C, Dalgleish AG, Kumar D. Review article: immune suppression and colorectal cancer. Aliment Pharmacol Ther 2006;24:1163-77 CrossRef Medline

28. Kawakami Y, Yaguchi T, Sumimoto H, et al. Cancer-induced immunosuppressive cascades and their reversal by molecular-targeted therapy. Ann N Y Acad Sci 2013;1284:80-86 CrossRef Medline

29. Pumhirun P, Wasuwat P. Anergy testing in patients with head and neck cancer. Asian Pac J Allergy Immunol 2003;21:189-92 Medline

30. Braaten K, Holcombe RF, Kim SS. Premedication with IV steroids effectively prevented anaphylactic reactions following ferumoxytol given as IV push in hematology and oncology patients. Am J Hematol 2015;90:E207 CrossRef Medline

31. Bircher AJ, Auerbach M. Hypersensitivity from intravenous iron products. Immunol Allergy Clin North Am 2014;34:707-23, x-xi CrossRef Medline

32. Rampton D, Folkersen J, Fishbane S, et al. Hypersensitivity reactions to intravenous iron: guidance for risk minimization and management. Haematologica 2014;99:1671-76 CrossRef Medline

33. Gahramanov S, Muldoon LL, Varallyay CG, et al. Pseudoprogression of glioblastoma after chemo- and radiation therapy: diagnosis by using dynamic susceptibility-weighted contrast-enhanced perfusion MR imaging with ferumoxytol versus gadoteridol and correlation with survival. Radiology 2013;266: 842-52 CrossRef Medline

34. Kanda T, Ishii K, Kawaguchi $\mathrm{H}$, et al. High signal intensity in the dentate nucleus and globus pallidus on unenhanced T1-weighted MR images: relationship with increasing cumulative dose of a gad- 
olinium-based contrast material. Radiology 2014;270:834-41 CrossRef Medline

35. Gahramanov S, Raslan AM, Muldoon LL, et al. Potential for differentiation of pseudoprogression from true tumor progression with dynamic susceptibility-weighted contrast-enhanced magnetic resonance imaging using ferumoxytol vs. gadoteridol: a pilot study. Int J Radiat Incol Biol Phys 2011;79:514-23 CrossRef Medline

36. Hamilton BE, Nesbit GM, Dosa E, et al. Comparative analysis of ferumoxytol and gadoteridol enhancement using T1- and T2weighted MRI in neuroimaging. AJR Am J Roentgenol 2011;197: 981-88 CrossRef Medline

37. Nasseri M, Gahramanov S, Netto JP, et al. Evaluation of pseudoprogression in patients with glioblastoma multiforme using dynamic magnetic resonance imaging with ferumoxytol calls RANO criteria into question. Neuro Oncol 2014;16:1146-54 CrossRef Medline

38. Dósa E, Tuladhar S, Muldoon LL, et al. MRI using ferumoxytol improves the visualization of central nervous system vascular malformations. Stroke 2011;42:1581-88 CrossRef Medline

39. Dósa E, Guillaume DJ, Haluska M, et al. Magnetic resonance imag- ing of intracranial tumors: intra-patient comparison of gadoteridol and ferumoxytol. Neuro Oncol 2011;13:251-60 CrossRef Medline

40. Farrell BT, Hamilton BE, Dósa E, et al. Using iron oxide nanoparticles to diagnose CNS inflammatory diseases and PCNSL. Neurology 2013;81:256-63 CrossRef Medline

41. Hamilton BE, Woltjer RL, Prola-Netto J, et al. Ferumoxytol-enhanced MRI differentiation of meningioma from dural metastases: a pilot study with immunohistochemical observations. J Neurooncol 2016;129:301-09 CrossRef Medline

42. Thompson EM, Guillaume DJ, Dósa E, et al. Dual contrast perfusion MRI in a single imaging session for assessment of pediatric brain tumors. J Neurooncol 2012;109:105-14 CrossRef Medline

43. UpToDate: Evidence-Based Clinical Decision Support System. Waltham, Massachusetts: Wolters Kluwer; 1992 [updated in 2016]. https://www.uptodate.com. Accessed April 3, 2017

44. ACR Committee on Drugs and Contrast Media. ACR Manual on Contrast Media. Version 10.2. Published June 2016. https://www. acr.org/ /media/ACR/Documents/PDF/QualitySafety/Resources/ Contrast-Manual/2016_Contrast_Media.pdf. Accessed April 3, 2017 